\title{
Management of space in the mixed dentition: The use of lip bumper
}

\author{
Ben Mohimd $\mathbf{H}^{1}$, Benyahia $\mathbf{H}^{2}$, Taleb $\mathbf{B}^{3}$, Zaoui $\mathrm{F}^{4}$ \\ ${ }^{1}$ Dr Hajar Ben Mohimd, Post Graduate Resident in Orthodontic Department, ${ }^{2}$ Dr Hicham Benyahia, Assistant Professor \\ in Orthodontic Department, ${ }^{3}$ Dr Bouchra Taleb, Professor in Oral Surgery Department, ${ }^{4}$ Dr Fatima Zaoui, Senior \\ Professor and Head of Orthodontic Department; all are affiliated with Mohammed V University in Rabat, Morocco.
}

Address for correspondence: Dr. Ben Mohimd Hajar, Department of Orthodontics, Center of Consultation and Dental Treatments, Faculty of Dentistry, Mohammed V University in Rabat. Allal El Fassi Avenue, Mohammed Jazouli Street Al Irfane City - BP 6212 Rabat Institutes. Morocco. E-mail: hajarbenmohimd@gmail.com

\begin{abstract}
Management of dental space problems continues to play a substantial role in interceptive orthodontics. In the mixed dentition, moderate crowding problems can be resolved through preservation of the Leeway space, regaining space or producing limited expansion. The lip bumper is a functional device that is used successfully to intercept developing dental and occlusal problems by allowing a proper development of the arch length and width for eruption of the permanent teeth. A nine-year-old female patient with the chief complaint of delayed eruption and lack of space in the left mandibular quadrant for the eruption of the entire permanent teeth. She was successfully treated in duration of 9 months with a lip bumper and expansion therapy.
\end{abstract}

Keywords: Interceptive orthodontics, Management of space, Crowding, Mixed dentition, Lip-bumper device.

\section{Introduction}

Crowding and irregularity remain one of the most prevalent components of a malocclusion in dental patients resolved by orthodontic treatment. It is characterized by an insufficient available space in the arch for the alignment of the entire permanent dentition. It can appear at various stages of dentition and can cause serious periodontal and occlusal consequences. Therefore, an early diagnosis is important in order to establish an effective interceptive approach [1]. A variety of treatment modalities have been described to gain space in mixed dentition and help to avoid the need for subsequent extractions. One of these methods is the lip bumper. It's a functional device made of .045 inch stainless steel wire often covered anteriorly with a plastic or acrylic shield. The wire is fixed to the first molars bands with a distance of two to three millimeters away from the incisors and two millimeters away from the premolars and has adjustment loops located just mesial to these tubes [2]. The lip bumper can resolve arch space deficiency either by maintaining the leeway space at the end of the mixed dentition or by developing the lower arch.

Manuscript received: $26^{\text {th }}$ March 2016

Reviewed: $10^{\text {th }}$ April 2016

Author Corrected; $24^{\text {th }}$ April 2016

Accepted for Publication: $13^{\text {th }}$ May 2016
The concept behind this appliance is based on the disruption of the equilibrium surrounding the dentition by keeping the musculature of the lower lip and cheeks away from the mandibular teeth, [2] this allows the lingual forces of the tongue to remain unbalanced, causing forward and lateral expansion of the mandibular dental arch. [3] Additionally, the pressure of the lower lip against the lip bumper during swallowing is transmitted directly to the lower molars. This pressure permits the distalization and distal tipping of the molars leading to arch length increasing [4] [5].

This mode of action not only increases arch dimensions, but also promotes the adaptation of soft tissues (lips and cheeks) to the mandibular expansion, thus providing better long-term stability unlike conventional expansion techniques [6] [7] [8].

The lip bumper can be used in both the maxillary and mandibular arch. However, maxillary appliances have been less frequently used. [9] In fact, R. Hasler and B. Ingervall [10] reported less effect on the anteriorpos3erior position of the first molars in maxillary dental arch compared to the mandibular, which was explained by the fact that the upper lip is weaker than the lower 
and less likely to generate enough force on the appliance unless rigorous muscle exercises are prescribed and followed. The mean pressure at rest from the lower lip on the lower incisors amounts to 9$12 \mathrm{~g} / \mathrm{cm} 2$ against $2-5 \mathrm{~g} / \mathrm{cm} 2$ from the upper lip on upper incisors [11] [12] [13].

Regarding the position of the lip bumper in relation to the incisor crowns, it can be positioned at different levels. Nevertheless, Hodge et al. [14] measured forces produced by lip bumpers placed in different positions and concluded that more force is produced when the wire lip bumper is placed four millimeters anterior to the incisors and at a more gingival position.
The lip bumper has been indicated in the mixed dentition to maintain (molar anchor) or increase arch length and perimeter, through labial incisors proclination and molars distalisation, [15] and to enhance incisor arch form position, when the lower incisors are lingually positioned (related to hypertonic lips); but it can also be used in lip habits breaking and neuro-muscular conditioning. [16].

The Present case report reveals the treatment outcome of a patient with insufficient space for the eruption of permanent teeth due to the mesial drift of the left molar who was treated using the lip bumper device.

\section{Case Report}

A 9-year-old female patient referred from Oral Surgery Department, to Orthodontics department located in the Center of Consultation and Dental Treatments (CCDT), Mohammed V University Rabat, Morocco.The chief complaint was delayed eruption and lack of space in the left mandibular quadrant, where deciduous teeth extraction $(73,74$ and 75$)$ was made months ago after the decompression of a dentigerous cyst.

Intraoral examination shows a passive space maintainer "lingual arch" which was pointless in this case given that the 36 already moved mesially (loss of anchorage) leading to a slight class III molar relationship. Early extractions of deciduous teeth has led to spaces loss, midline shift, and bi-retrusion of upper and lower incisors causing important overbite, which can adversely affect mandibular and facial growth [Figure 1].
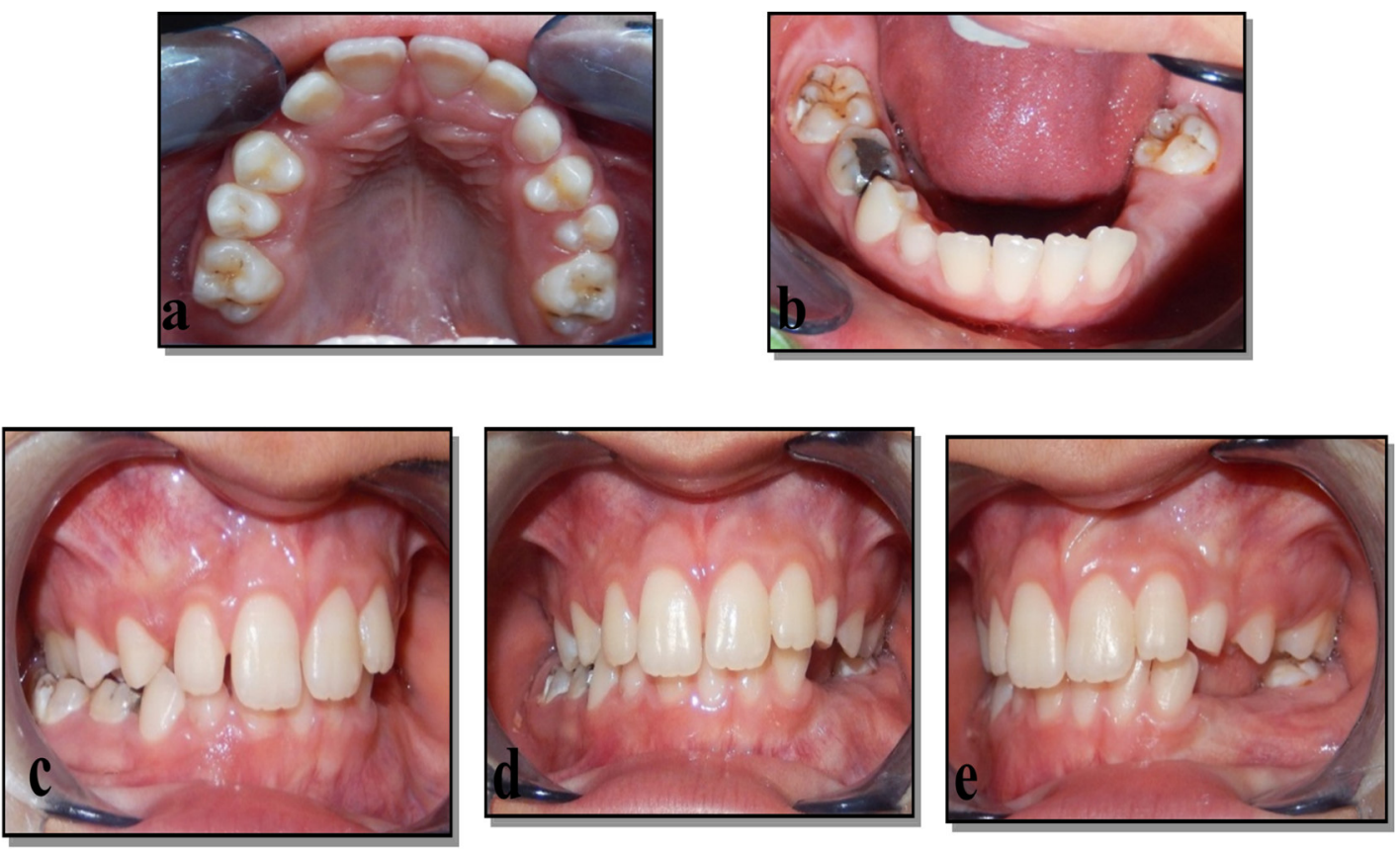

Figure 1 a-e: Pre-treatment intra-oral photographs

The panoramic radiograph revealed signs of maxillary canines' retention, and the mesial displacement of the mandibular left first molar leading to delayed eruption and retention of canine and premolars [Figure 2]. Cephalometric examination reveals skeletal Class I malocclusion with hyperdivergent facial pattern tendency hence the importance of early interception [Figure 3] [Table1]. 


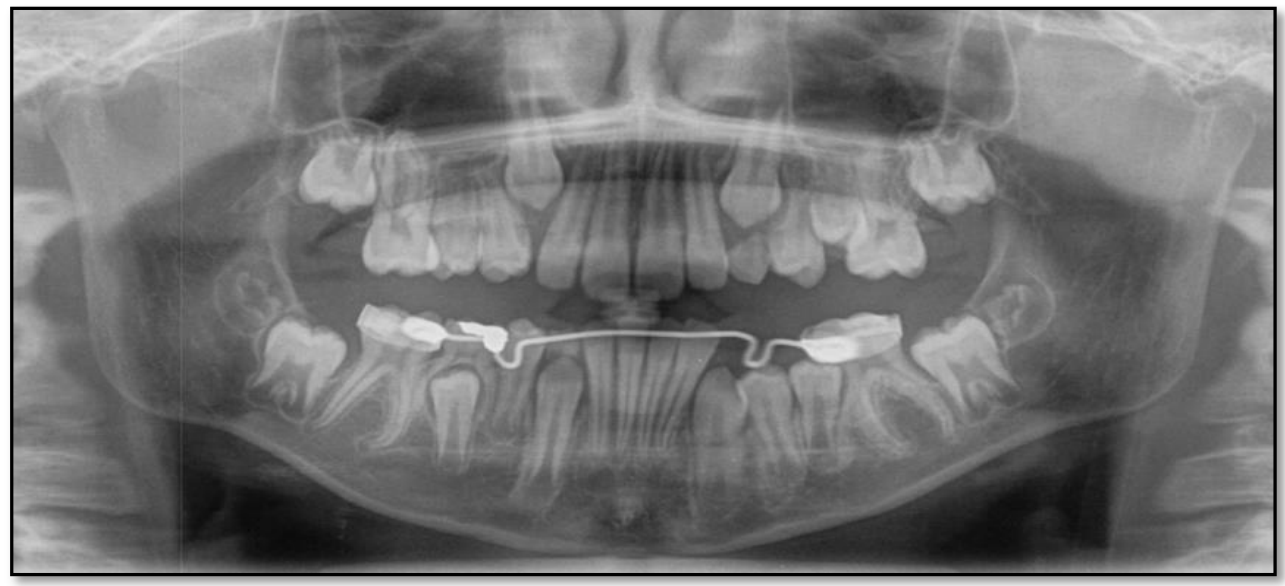

Figure 2: Panoramic radiograph showed mesial drift of the left first molar and canine's retention

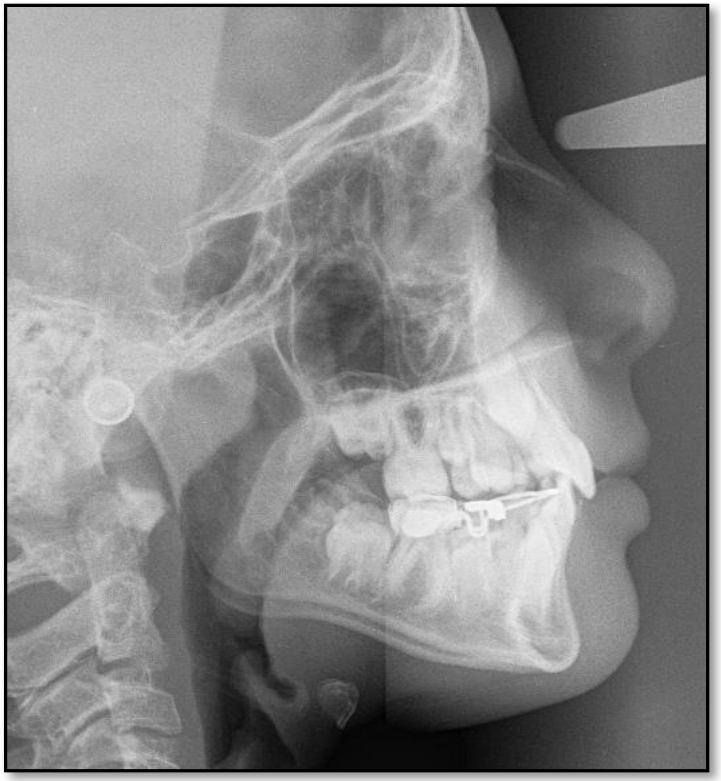

Table 1: pre-treatment cephalometric values.

\begin{tabular}{|l|l|}
\hline Value * & Pre-treatment \\
\hline SNA & $80^{\circ}$ \\
\hline SNB & $76^{\circ}$ \\
\hline ANB & $4^{\circ}$ \\
\hline AoBo & $4 \mathrm{~mm}$ \\
\hline UI-NA angle & $17^{\circ}$ \\
\hline UI-NA distance & $3 \mathrm{~mm}$ \\
\hline LI-NB angle & $18^{\circ}$ \\
\hline LI-NBdistance & $4 \mathrm{~mm}$ \\
\hline GoGnSn & $38^{\circ}$ \\
\hline PogtoNB & $1,25 \mathrm{~mm}$ \\
\hline
\end{tabular}

Figure 3: profile teleradiograph

*SNA = Sella-nasion-A point angle; SNB = Sella-nasion-B point angle; $\mathrm{ANB}=\mathrm{A}$ point, nasion, $\mathrm{B}$ point angle; GoGnSn = Gognion- Gnathion (mandibular plan)-Sella-nasion; UI-NA = upper incisor nasion-A point angle and distance; $\mathrm{LI}-\mathrm{NB}=$ lower incisor-nasion-B point angle and distance; PogtoNB $=$ chin prominence - nasion- $\mathrm{B}$ point distance

Treatment objective was at first, to regain mandibular space for eruption of the delayed teeth with the use of a lip bumper that will help to upright mandibular molar and correct overbite by tipping labially the lower incisors [Figure 4]. Secondly, to expand the maxilla and enhance arch form by setting orthodontic appliance which would be propitious to the eruption of canines and the harmonization of facial growth [Figure 5].

After 9 months of bumper wear, the device provided a sufficient space for the harmonious eruption of the permanent teeth [Figure 4]. Then the orthodontic appliance corrected maxillary arch form setting a class I occlusion relationship awaiting canines' eruption [Figure 5]. 


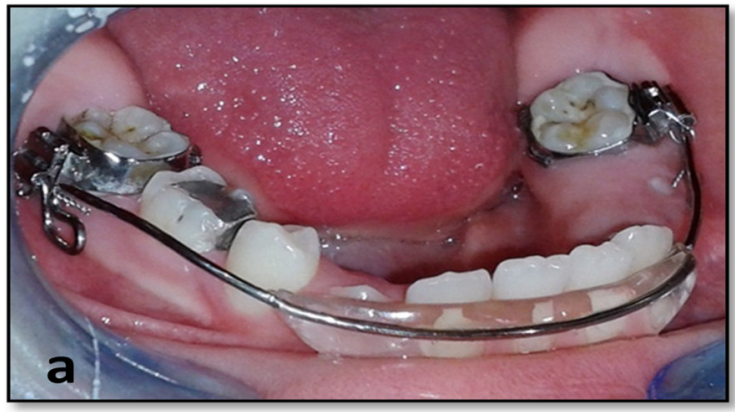

a: lip bumper in place

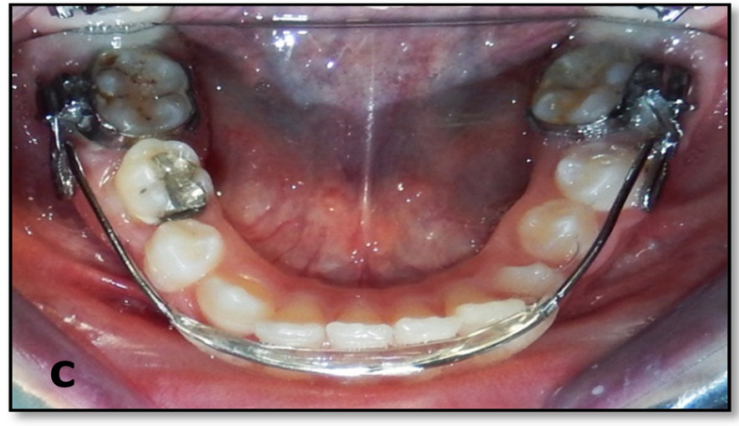

c: After 6 months

Figure 4: Evolution of the case after lip bumper wear

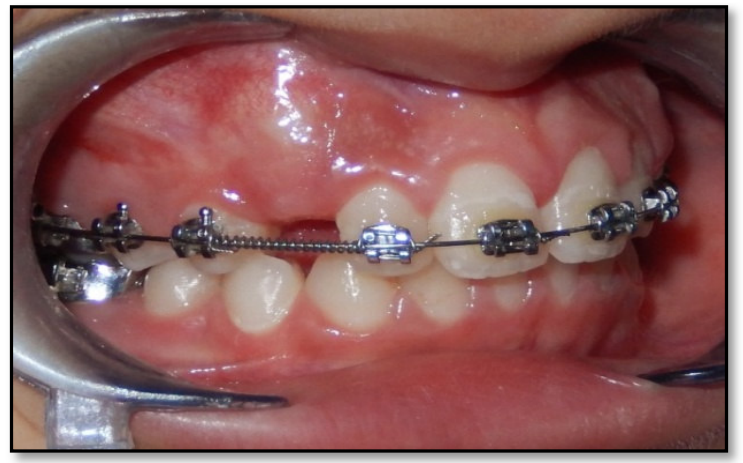

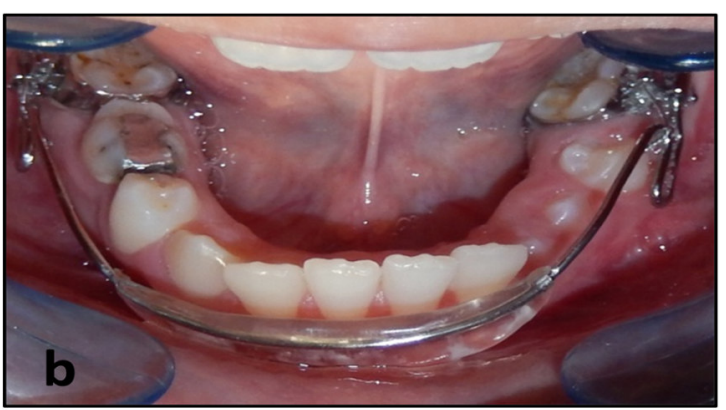

b: After 3 months

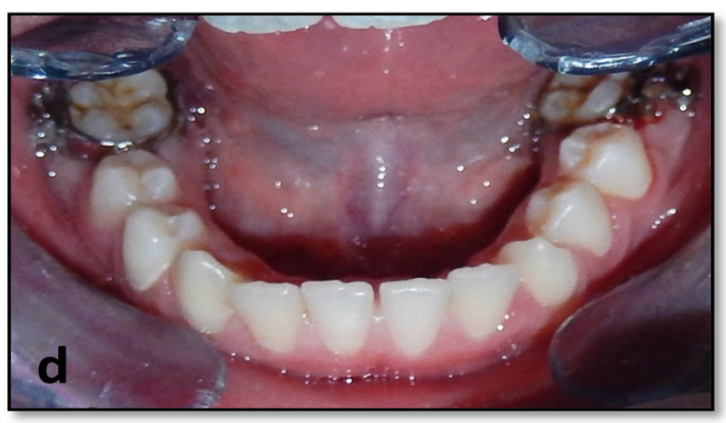

d: After 9 months

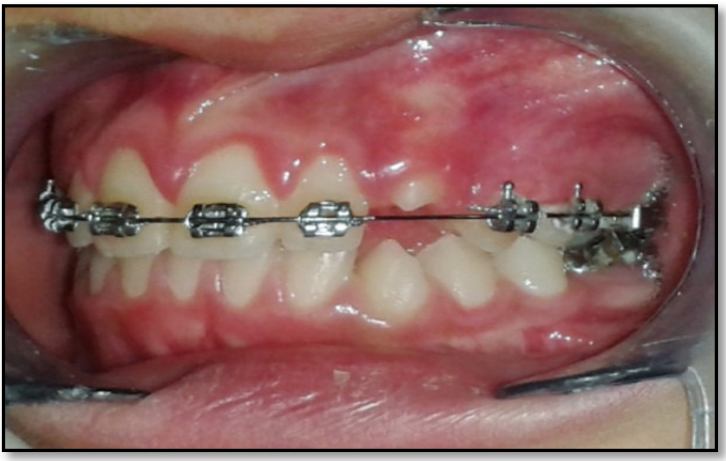

Figure-5a and 5b: Post-interceptive treatment and orthodontic monitoring of maxillary canines eruption

\section{Discussion}

Orthodontists have always been faced with the problem of straightening crowded teeth. A variety of interceptive treatment modalities have been advocated in the mixed dentition to reduce this crowding, some of which include: tooth extraction, expansion, interproximal enamel reduction, flaring incisors and uprighting molars [2].

The lip bumper is an effective appliance which allows the management of a mild to moderate crowding $(<5 \mathrm{~mm})$ by maintaining and/or increasing arch length.
[1] Any increase in arch length generally reflects both distal movement of the molars and labial movement of the incisors. [17]. In our case, the use of the lip bumper has allowed at first, the restoration of the space that has been lost through mesial drift of the molar and secondly, the anteroposterior and transverse expansion of the lower arch to ensure the harmonious accommodation of the erupting teeth.

Several studies were performed to determine the effects of the lip bumper therapy on mandibular arch 
dimensions and to quantify experimental variations. The effects were discussed under three headings: molar distalisation, arch width and incisor proclination.

The magnitude and consistency, with which this effect has been reported, as well as the sources of arch length increases, vary among observers.

Subtelny and Sakuda [4] reported in a study of twentyfive cases, a distal molar movement in twenty-two. In their opinion, the use of the lip bumper in the lower arch is synonymous with that of a headgear appliance in the upper arch.

Osborn et al. [15] also quantified several dimensional changes that occur during the use of the lip bumper. In their study of 32 patients in the late mixed and earlier permanent dentitions, they noticed that, an average arch circumference increased by $4.1 \mathrm{~mm}$ and the arch width by $2 \mathrm{~mm}$ at the canines, $2.5 \mathrm{~mm}$ at the first premolars, $2.4 \mathrm{~mm}$ at the second premolars, and $2 \mathrm{~mm}$ at the first molars. They also reported an increase in the arch length of $1.2 \mathrm{~mm}$.

Most of the studies of the lip bumper effects in the lower arch showed that the increase of arch perimeter is more related to an increase in arch width rather to arch length. [15][18][19] [20].

In a recent study; where dental casts as well as lateral and tomographic radiographics were used to determine the effect of six months of continuous lip bumper therapy on patients with mild to moderate crowding, Davidovitch and al. [6] reported more effect on the molar compared with that remarked with conventional cephalometry. In fact, they demonstrated that besides the passive increase in the transverse dimension, arch length, arch perimeter, and incisor proclination, mandibular molars tip distally $3.4^{\circ}$ and distalize 0.61 $\mathrm{mm}$ which allowed the resolution of an average of four millimeters of crowding more than the control group.

\section{Conclusion}

The lip bumper is an effective functional appliance that is used successfully to intercept developing dental and occlusal problems ${ }^{[16]}$ and as an adjunct to orthodontic therapy.

In selected patients with crowded lower arches, the use of the lip bumper, properly timed and in conjunction with an accurate diagnosis and complete records, can prevent unnecessary loss in arch length by either maintaining and / or increasing arch dimensions.

In this case report, the use of the lip bumper did ensure the gain of space through the distal movement of the molarsand the incisors. This gain of space allowed on one hand a harmonious development of permanent teeth and on the other hand to eliminate the need for subsequent extraction during permanent dentition.

\section{Funding: Nil, Conflict of interest: Nil Permission from IRB: Yes}

\section{References}

1. Ngan P, Alkire RG, Fields H Jr. Management of space problems in the primary and mixed dentitions. $\mathrm{J}$ Am Dent Assoc. 1999 Sep;130(9):1330-9.

2. Murphy CC, Magness WB, English JD, FrazierBowers SA, Salas AM. A longitudinal study of incremental expansion using a mandibular lip bumper. Angle Orthod. 2003 Aug;73(4):396-400.

3. Bjerregaard J, Bundgaard AM, Melsen B. The effect of the mandibular lip bumper and maxillary bite plate on tooth movement, occlusion and space conditions in the lower dental arch. Eur J Orthod. 1980;2(4):257-65.

4. Subtelny JD, Sakuda M. Muscle function, oral malformation, and growth changes. Am J Orthod. 1966 Jul;52(7):495-517.

5. Celentano G, Longobardi A, Cannavale R, Perillo L. Mandibular lip bumper for molar torque control. Prog Orthod. 2011;12(1):90-2. doi: 10.1016/j.pio.2011. 02. 009. Epub 2011 Mar 29.

6. Davidovitch M, McInnis D, Lindauer SJ. The effects of lip bumper therapy in the mixed dentition. Am J Orthod Dentofacial Orthop. 1997 Jan;111(1):52-8.

7. Shellhart WC, Moawad MI, Matheny J, Paterson RL, Hicks EP. A prospective study of lip adaptation during six months of simulated mandibular dental arch expansion. Angle Orthod. 1997; 67(1):47-54.

8. Hodge JJ, Nanda RS, Ghosh J, Smith D. Forces produced by lip bumpers on mandibular molars. Am J Orthod Dentofacial Orthop. 1997 Jun;111(6):613-22.

9. Denholtz M. A method of harnessing lip pressure to move teeth. J Am Soc Study Orthod 1:16-35,1963. 
10. Häsler R, Ingervall B. The effect of a maxillary lip bumper on tooth positions. Eur J Orthod. 2000 Feb; 22(1):25-32.

11. Thüer U, Ingervall B. Pressure from the lips on the teeth and malocclusion. Am J Orthod Dentofacial Orthop. 1986 Sep;90(3):234-42.

12. Thüer U, Ingervall B. Effect of muscle exercise with an oral screen on lip function. Eur J Orthod. 1990 May;12(2):198-208.

13. Thüer U, Janson T, Ingervall B. Application in children of a new method for the measurement of forces from the lips on the teeth. Eur J Orthod. 1985 Feb;7(1):63-78.

14. Hodge JJ, Nanda RS, Ghosh J, Smith D. Forces produced by lip bumpers on mandibular molars. Am J Orthod Dentofacial Orthop. 1997 Jun;111(6):613-22.

15. Osborn WS, Nanda RS, Currier GF. Mandibular arch perimeter changes with lip bumper treatment. Am J Orthod Dentofacial Orthop. 1991 Jun;99(6):527-32.
16. Ghafari J. A lip-activated appliance in early orthodontic treatment. J Am Dent Assoc. 1985 Nov;111(5):771-4.

17. Hashish DI, Mostafa YA. Effect of lip bumpers on mandibular arch dimensions. Am J Orthod Dentofacial Orthop. 2009 Jan;135(1):106-9. doi: 10.1016/j. ajodo. 2007.10.038.

18. Nevant CT, Buschang PH, Alexander RG, Steffen JM. Lip bumper therapy for gaining arch length. Am J Orthod Dentofacial Orthop. 1991 Oct;100(4):330-6.

19. Werner SP, Shivapuja PK, Harris EF. Skeletodental changes in the adolescent accruing from use of the lip bumper. Angle Orthod. 1994;64(1):13-20; discussion 21-2.

20.Grossen J, Ingervall B. The effect of a lip bumper on lower dental arch dimensions and tooth positions. Eur J Orthod. 1995 Apr;17(2):129-34.

\section{How to cite this article?}

Ben Mohimd H, Benyahia H, Taleb B, Zaoui F. Management of space in the mixed dentition: The use of lip bumper. Int J Pediatr Res.2016;3(6):440-445.doi:10.17511/ijpr.2016.i06.12. 